\title{
KEEFEKTIFAN PEMBELAJARAN IPA MENGGUNAKAN MODEL COMPLETTE SENTENCE BERBANTU CARD TEHADAP HASIL BELAJAR SISWA KELAS III SDN NGELOWETAN KABUPATEN DEMAK
}

\author{
Henry Januar Saputra ${ }^{1}, *$, Zaenal Arifin², Rezza Aldi Ferdiansa ${ }^{3}$ \\ 1 Universitas PGRI Semarang Indonesia \\ 2 Universitas PGRI Semarang Indonesia \\ 3 Universitas PGRI Semarang Indonesia
}

\begin{abstract}
Abstrak
This study aims to determine the effectiveness of learning science using Compelette Sentence learning model in terms of comparison the average result of learning and mastery learning material science of energy and its use. The research was conducted in SDN Ngelowetan on 17 to 21 April 2017. The method used in this research is to study the design of pretest-posttest control group design with a saturated sample. The instrument will involve a total of 20 multiple-choice test items. Method of collection using method of documentation and test method. Technique of data analysis done with mastery learn and $t$ test. Results showed that the experimental and control groups on average there are differences in learning outcomes between students who get Complette Sentence learning model and students do not get the learning with the learning model Complette Sentence. Learning outcomes in the experimental group reached an average of 81.50 with the percentage of $86.67 \%$ mastery learning. While the average of learning outcomes in the control group was 75.18 with the percentage of mastery learning as much as $60.71 \%$.
\end{abstract}

Keywords:

Learning Outcomes,

Learning Model

Complete Sentence

Assisted Card

\section{Pendahuluan}

Pendidikan adalah salah satu bentuk perwujudan kebudayaan manusia yang dinamis dan sarat perkembangan. Oleh karena itu, perubahan dan perkembangan pendidikan adalah hal yang seharusnya terjadi dan sejalan dengan perubahan budaya kehidupan dalam rangka mencapai tujuan pembangunan nasional. Undang-Undang No 20 Tahun 2003 yang menyebutkan: Pendidikan nasional berfungsi mengembangkan kemampuan dan membentuk watak serta peradaban bangsa yang bermartabat dalam rangka mencerdaskan kehidupan bangsa, bertujuan untuk berkembangnya potensi peserta didik agar menjadi manusia yang beriman dan bertakwa kepada Tuhan Yang Maha Esa, berakhlak mulia, sehat, berilmu, cakap, kreatif, mandiri, dan menjadi warga negara yang demokratis serta bertanggung jawab.

Sekolah sebagai lembaga pendidikan yang merupakan tempat terjadinya proses pembelajaran diharapkan mampu mengembangkan keperibadian dan segenap potensi siswa agar mereka dapat tumbuh dan berkembang sesuai dengan tujuan pendidikan nasional (Susanto, 2013). Tujuan tersebut dapat tercapai melalui pendidikan dan pengajaran berbagai disiplin ilmu. Salah satu disiplin ilmu tersebut adalah Ilmu Pengetahuan Alam (IPA).

Pendidikan IPA merupakan salah satu kompetensi yang harus dimiliki siswa, karena pendidikan IPA memiliki peranan yang penting dalam meningkatkan mutu pendidikan (Jaya, 2014). Ilmu Pengetahuan Alam (IPA) yang sering disebut dengan pendidikan sains merupakan salah satu mata pelajaran pokok dalam kurikulum pendidikan di Indonesia, termasuk pada jenjang sekolah dasar (Agustini, 2014).

IPA merupakan salah satu mata pelajaran yang berbasis ilmu pengetahuan yang bersumber dari alam. IPA berupaya membangkitkan minat manusia untuk meningkatkan kecerdasan dan pemahaman mengenai alam dan seisinya. IPA dapat membuka rasa ingin tahu peserta didik secara alami. Hal tersebut 
dapat mengembangkan kemampuan peserta didik untuk mencari tahu sesuatu hal, bertanya, berpikir secara alamiah dan menemukan jawaban dengan sendirinya secara alami.

Pembelajaran IPA di SD seharusnya dilakukan dengan penyelidikan-penyelidikan sederhana dan bukan hafalan terhadap kumpulan konsep IPA. Kegiatan penyelidikan yang dimaksud pada pendapat diatas adalah kegiatan pengamatan atau praktikum sederhana. Dengan demikian, pelaksanaan pembelajaran di SD seharusnya tidak hanya menekankan pada pemahaman konsep yang merupakan bagian dari produk IPA, tetapi juga memperhatikan bagaimana proses menemukan konsep tersebut. Pada umumnya IPA merupakan pembelajaran yang dianggap paling sulit dipahami oleh sebagian siswa. Anggapan tersebut dapat dilihat dari kesalahan yang terjadi karena beberapa faktor, yaitu kesalahan yang bersumber dari guru dan kesalahan yang bersumber dari siswa. Kesalahan yang bersumber dari guru, misalnya guru belum menerapkan pembelajaran yang konstruktif dan kesalahan yang bersumber dari siswa, misalnya siswa tidak fokus mengikuti proses pembelajaran.

Berdasarkan obsevasi yang dilakukan peneliti di kelas III SDN Ngelowetan 01 Demak, guna mengetahui permasalahan yang terdapat didalam proses pembelajaran yang berlangsung, ditemukan beberapa permasalahan yang sering muncul dalam kegiatan pembelajaran. Diantaranya siswa yang suka bermain sendiri saat pembelajaran, sistem kerja kelompok yang belum berjalan sebagaimana mestinya karena ketidakcocokan antar anggota kelompok, partisipasi siswa lebih condong dilakukan oleh siswa yang pandai saja sehingga antusias dan keaktifan siswa belum menyeluruh.

Untuk memecahkan masalah pembelajaran tersebut, terdapat alternatif metode pembelajaran yang dapat mendorong aktivitas siswa dalam belajar sehingga dapat mempengaruhi hasil belajar siswa yaitu model/metode yang menarik perhatian siswa dan juga dapat mendorong keaktifan dan kerja kelompok siswa dalam belajr sehingga dapat meningkatkan belajar siswa yaitu dengan menggunakan model complette centence. Pemilihan model complette centence ini didasarkan pada berbagai pertimbangan sebab model ini merupakan model pembelajaran yang diperkaya dengan kerja sama, berfikir cepat dan permainan, dengan menggunakan model complette centence siswa dilibatkan secara aktif dalam penyajian materi pelajaran.

Dimana model complette sentence ini siswa disuruh melengkapi kalimat yang belum lengkap dengan kunci jawaban yang tersedia, kemudian siswa berdiskusi secara berkelompok yang dimana kelompok sudah dibagi menjadi 3 orang perkelompok, setelah itu tiap siswa membaca sampai mengerti atau hafal dengan jawaban yang benar.

Salah satu sintaks model ini adalah guru menyajikan beberapa kata kunci sesuai dengan materi yang disajikan. Begitu pula pada kelebihan dari model ini adalah siswa lebih memahami kata kunci dari materi pokok pembelajaran. Dengan kata lain inti dari model pembelajaran Concept Sentence adalah adanya penyajian beberapa kata kunci dalam membelajarkan siswa sehingga siswa lebih memahami kata kunci dari materi pokok pembelajaran. Penggunaan model ini berpotensi meningkatkan hasil belajar siswa. Temuan ini didukung oleh penelitian Widodo (2017) mengatakan ada perbedaan pengaruh penggunaan Model Pembelajaran Complete Sentences didukung media gambar dibanding model konvensional.

Berdasarkan ulasan di atas, akan diteliti mengenai "Keefektifan Pembelajaran IPA Menggunakan Model Complette Sentence Berbantu Card Terhadap Hasil Belasr Siswa Kelas III SDN Ngelowetan Kabupaten Demak".

\section{Metode Penelitian}

Penelitian ini telah dilaksanakan pada siswa kelas III SDN Ngelowetan Kabupaten Demak. Penelitian ini dilaksanakan pada tanggal 17-20 April pada semester 2 tahun pelajaran 2016/2017. Variabel penelitian adalah suatu atribut atau sifat atau nilai dari orang, obyek atau kegiatan yang mempunyai variasi tertentu yang ditetapkan oleh peneliti untuk dipelajari dan kemudian ditarik kesimpulannya (Sugiyono, 2010: 60).

Dalam penelitian ini terdapat dua variabel, yaitu variabel bebas dan variabel terikat.

1. Variabel bebas $(x)$

Menurut Sugiyono (2010: 61) variabel bebas merupakan variabel yang mempengaruhi atau yang menjadi sebab perubahannya atau timbulnya variable dependen (terikat). Variabel bebas dalam penelitian ini berupa penggunaan model pembelajaran Complette Sentence berbantu Card.

2. Variabel terikat (y)

Menurut Sugiyono (2010: 61) variabel terikat merupakan variabel yang dipengaruhi atau yang menjadi akibat, karena adanya variabel bebas. Variabel terikat dalam penelitian ini adalah Pembelajaran IPA terhadap hasil belajar siswa kelas III.

Penelitian ini menggunakan metode jenis penelitian kuantitatif atau eksperimen dimana dalam proses pengumpulan data dalam bentuk tes. Metode tes digunakan untuk memperoleh data hasill belajar 
kelas III pada materi energi dan penggunaannya. Desain penelitian yang digunakan adalah True Experimental Design. Dalam penelitian ini, peneliti menggunakan bentuk design dari jenis pretest-posttest Control Group Design.

Populasi dalam penelitian ini adalah seluruh siswa kelas III di SDN Ngelowetan Demak tahun ajaran 2016/2017 dengan total 58 siswa yang terdiri dari dua kelas yaitu kelas III A berjumlah 28 siswa dan kelas III B 30 siswa. Sampel penelitian ini adalah kelas III A yang berjumlah 28 anak dan kelas III B yang berjumlah 30 anak. Cara menentukan kelas kontrol dan kelas eksperimen, yaitu dengan cara acak yaitu mengundi 2 kelas melalui pengambilan lintingan kelas kontrol dan eksperimen. Kelas yang pertama sebagai kelas kontrol, yaitu mendapatkan pembelajaran dengan metode ceramah dan kelas kedua sebagai kelas eksperimen, yaitu mendapatkan pembelajaran dengan metode pembelajaran complette sentence. Sedangkan penentuan sampel pada penelitian ini dilakukan dengan teknik non probability sampling. Teknik yang digunakan pada sampel ini menggunakan sampling jenuh.

Teknik pengumpulan data menggunakan nontes diantaranya observasi dan dokumentasi. Dalam peneliti melibatkan diri dalam situasi subjek yang diteliti sebelum dan selama dilaksanakan pembelajaran, menggunakan dokumentasi dan tes tertulis.

Instrumen penelitian berbentuk tes. Adapun menentukan instrumen dengan langkah-langkah sebagai berikut: (a) tahapan persiapan, meliputi pembatasan materi yang akan diujikan, menentukan alokasi waktu, membuat kisi-kisi soal, membuat soal dengan kisi-kisi soal yang ada, (b) tahap pelaksanaan, setelah persiapan yaitu dilakukan pembuatan perangkat uji coba maka dapat dilakukan uji coba instrumen yang dilaksanakan di kelas III SD Negeri Mijen 1 Demak, dan (c) tahap analisis. Setelah melaksanakan uji coba, maka diadakan analisis uji coba yang meliputi validitas, reliabilitas, daya pembeda dan tingkat kesukaran. Instrumen ranah kognitif dalam penelitian ini berupa soal pilihan ganda yang akan digunakan untuk soal pretest dan posttest.

Dalam penelitian kuantitatif, teknik analisis data yang digunakan diarahkan untuk menjawab rumusan masalah atau menguji hipotesis yang telah dirumuskan dalam proposal (Sugiyono, 2010: 333). Adapun rumus yang digunakan yaitu menggunakan uji normalitas data yang terdiri dari uji normalitas data awal/pretest dan uji normalitas data akhir/Posttest. Kemudian mencari homogenitas data, apakah data tersebut homogeny atau tidak. Kemudian uji t-test atau uji hipotesis dan selanjutnya uji ketuntasan belajar yant terdiri dari uji ketuntasan belajar individu apabila menguasai kompetensi atau mencapai tujuan pembelajaran minimal 65\% dari seluruh tujuan pembelajaran dan uji ketuntasan belajar klasikal apabila mampu menyelesaikan atau mencapai minimal 65\%, sekurang-kurangnya 85\% dari jumlah peserta didik yang ada di kelas tersebut.

\section{Hasil Dan Pembahasan}

\section{Hasil}

A. Uji Persyaratan Analisis Data

1. Analisis hasil awal

a. Uji normalitas

Uji normalitas pada analisis hasil awal digunakan untuk mengetahui apakah hasil awal (pretest) berdistribusi normal atau tidak.

Tabel 1.1 Rekapitulasi Uji Normalitas Awal (Pretest) Kelompok Eksperimen dan Kelompok Kontrol

\begin{tabular}{cccc}
\hline Kelompok & N & Lo & Ltabel \\
\hline Eksperimen & 30 & 0,143 & 0,16 \\
Kontrol & 28 & 0,078 & 0.17 \\
\hline
\end{tabular}

Berdasarkan tabel di atas terlihat bahwa $\mathrm{L}_{0}<$ Ltabel pada taraf $5 \%$ dan $\quad \mathrm{n}_{1}=30$, dan $\mathrm{n}_{2}=28$ baik untuk kelompok eksperimen dan kelompok kontrol sehingga populasi berdistribusi normal.

b. Uji homogenitas

Untuk mengetahui apakah sampel diperoleh berasal dari populasi yang homogen maka perlu diuji homogenitas dengan uji Barlett. Berdasarkan perhitungan diperoleh $\chi_{\text {hitung }}^{2}$ 0,037. Hasil tersebut kemudian dibandingkan dengan $\chi_{\text {tabel }}^{2}$. Untuk $\alpha=5 \%$ dengan dk $=(\mathrm{n}-1)=(2-1)=1$ 
dari harga kritik Chi Kuadrat diperoleh $\chi_{\text {tabel }}^{2}=3,841$. Karena $\chi_{\text {hitung }}^{2}<\chi_{\text {tabel }}^{2}$ yaitu $(0,037<3,841)$ maka $\mathrm{H}_{0}$ diterima, artinya kedua sampel berasal dari populasi yang homogen.

2. Analisis Hasil Akhir

a. Uji Normalitas

Uji normalitas pada analisis hasil awal digunakan untuk mengetahui apakah hasil akhir (postest) berdistribusi normal atau tidak.

Kriteria dalam uji normalitas ini adalah:

$\mathrm{L}_{0}<$ Ltabel, maka populasi berdistribusi normal

$\mathrm{L}_{0} \geq \mathrm{Ltabel}$, maka populasi tidak berdistribusi normal

Tabel 1.2 Rekapitulasi Uji Normalitas Akhir (Postest) Kelompok Eksperimen dan Kelompok Kontrol

\begin{tabular}{cccc}
\hline Kelompok & $\mathrm{N}$ & Lo & Ltabel \\
\hline Eksperimen & 30 & 0,156 & 0,16 \\
Kontrol & 28 & 0,138 & 0,17 \\
\hline
\end{tabular}

Berdasarkan tabel di atas terlihat bahwa $\mathrm{L}_{0}<$ Ltabel pada taraf $5 \%$ dan $\quad \mathrm{n}_{1}=30$, dan $\mathrm{n}_{2}=28$ baik untuk kelompok eksperimen dan kelompok kontrol sehingga populasi berdistribusi normal.

b. Uji Homogentias

Untuk mengetahui sampel berasal dari populasi yang homogen maka kedua kelas perlu diuji homogenitas dengan menggunakan uji Bartlett. Hasil perhitungan diperoleh $\chi_{\text {hitung }}^{2}$ 0,085 Setelah memperoleh $\chi_{\text {hitung, }}^{2}$, hasil tersebut kemudian dibandingkan dengan $\chi_{\text {tabel }}^{2}$. Untuk $\alpha=5 \%$ dengan $\mathrm{dk}=$ $(\mathrm{k}-1)=(2-1)=1$ dari harga kritis Chi Kuadrat diperoleh $\chi_{\text {tabel }}^{2}=3.841$. Karena $\chi_{\text {hitung }}^{2}<\chi_{\text {tabel }}^{2}$ yaitu $(0,085<3.841)$ maka $\mathrm{H}_{0}$ diterima, artinya kedua sampel berasal dari populasi yang homogen.

B. Hasil Pengujian Hipotesis

1. Uji-t satu pihak

Berdasarkan Tabel 4.6 uji t untuk satu pihak dapat dilihat mengenai perhitungan $t$-test (posttest) antara kelas kontrol dengan kelas eksperimen.

Tabel 4.6 Uji T

\begin{tabular}{ccc}
\hline Keterangan & Kelas Eksperimen & Kelas Kontrol \\
\hline $\bar{x}$ & 81,50 & 75,18 \\
\hline $\mathrm{N}$ & 30 & \\
\hline $\mathrm{S}$ & 162,327 & \\
\hline $\mathrm{t}_{\text {hitung }}$ & 1.941 & \\
\hline $\mathrm{t}_{\text {table }}$ & 1.70 & \\
\hline
\end{tabular}

Dari tabel 4.7 diperoleh $\bar{x}$ kelas eksperimen $=81,50$ dan $\bar{x}$ kelas kontrol $=75,18$, dengan $\mathrm{n}$ kelas eksperimen 30 dan $\mathrm{n}$ kelas kontrol 28, $\mathrm{S}$ gabungan $=148.8208128, \mathrm{t}$ hitung $=1,941$ dan $\mathrm{t}_{\text {tabel }}=1,70$.

Berdasarkan perhitungan tersebut di peroleh $\mathrm{t}$ hitung $>\mathrm{t}$ tabel yaitu 1,941 $>1,70$, maka Ho ditolak. Jadi Kesimpulannya hasil belajar yang dikenai model Complette Sentence lebih efektif dari pada pembelajaran Konvensioal.

Adapun hasil data yang diperoleh pada penelitan dikelas kontrol dan kelas eksperimen dapat dilihat pada Diagram 1.1 dibawah ini. 


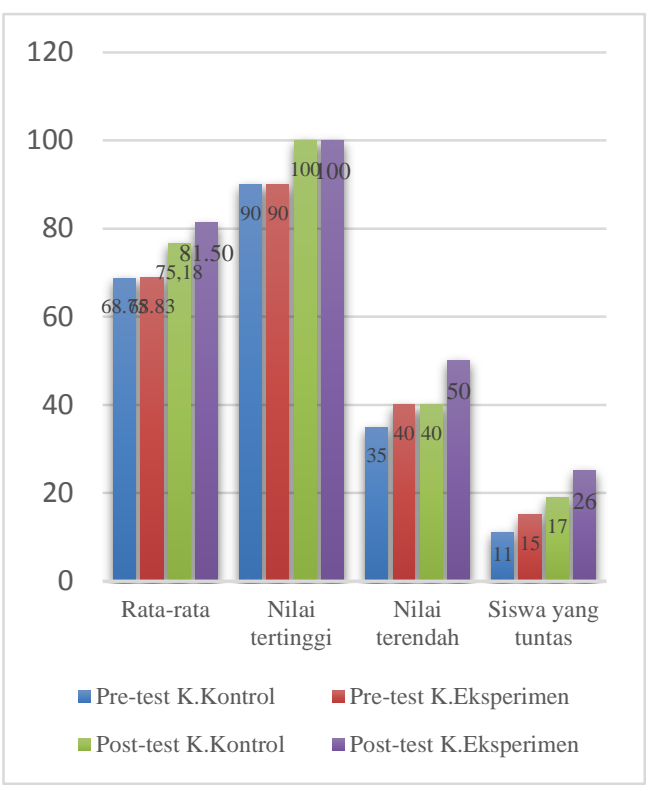

Gambar 1. 1 Diagram

Dari Diagram 1.1 dapat diketahui bahwa perbedaan hasil pelaksanaan pre-test di kelas kontol dan kelas eksperimen dengan banyak siswa yang tuntas pada kelas kontrol sebanyak 11 siswa sementara pada kelas eksperimen sebanyak 15 siswa. Selanjutnya pada posttest terlihat peningkatan yang pada kedua kelas tersebut. Pada kelas kontrol mempunyai kenaikan rata-rata kelas 75,18 sedangkan kelas eksperimen mempunyai rata-rata kelas 81,50. Kemudian untuk ketuntasan siswanya pada kelas kontrol sebanyak 17 siswa dan kelas eksperimen naik menjadi 26 siswa. Begitu juga dengan nilai tertinggi dan terendah pada kelas kontrol dan eksperimen terjadi kenaikan yaitu nilai tertinggi pada kelas kontrol sebesar 100 dan pada kelas eksperimen 100 sedangkan nilai terendahnya kelas kontrol 40 dan 50 untuk kelas eksperimen.

Kendala yang ditemukan dalam penelitian ini adalah penyampaian cara menggunakan model pembelajaran complette sentence ini kepada guru karena guru hanya mengenal beberapa model pembelajaran saja. Masih didominasi oleh model pembelajaran konvensional dan guru menganggap bahwa model konvensional lebih mampu di terima oleh siswa. Kendala lain adalah pembagian waktu antara penelitian pada sekolah yang dijadikan kelas eksperimen dengan sekolah yang dijadikan sebagai kelas kontrol.

\section{Pembahasan}

Pada penelitian ini peneliti menggunakan model pembelajaran Complette Sentence berbantu card yang dibutuhkan pada materi energi dan penggunaannya sehingga siswa dapat mempermudah dalam proses perbelajaran yang diterima siswa. Penelitian ini bertujuan untuk mengetehaui keefektifan pelajaran IPA menggunakan model pembelajaran Complette Sentence berbantu card terhadap hasil belajar siswa kelas III SDN Ngelowetan.

Pada penelitian ini peneliti menggunakan rancangan penelitian True Experimental Design dengan bentuk pretest-postest control group design dan hanya pada desain ini kelompok eksperimen maupun kelompok kontrol tidak dipilih secara random. Jadi pada penelitian ini terdapat dua kelas yakni kelas eksperimen (yang dikenai model pembelajaran Complette Sentence berbantu card) dan kelas kontrol (pembelajaran konvensional). Berdasarkan analisis data yang telah diuraikan, kita ketahui bahwa dari uji t satu pihak dapat disimpulkan bahwa pada hipotesis terdapat keefektifan pelajaran IPA menggunakan model pembelajaran Complette Sentence berbantu card terhadap hasil belajar siswa III SDN Ngelowetan dengan $t_{\text {hitung }}>t_{\text {tabel }}$ yaitu $(1,941>1,70)$.

Hasil uji t tersebut juga diperkuat oleh ketuntasan belajar kelas eksperimen yakni sebanyak 30 peserta didik mencapai ketuntasan belajardengan persentase ketuntasan $86,67 \%$ dan rata-rata 81,50. Sedangkan pada kelas kontrol hanya terdapat 28 peserta didik yang tuntas hasil belajarnya dengan persentase ketuntasan 60,71\% dan nilai rata-rata 75,18. Dengan perbedaan persentase ketuntasan antara kelas eksperimen dan kelas kontrol, perbedaan rata-rata nilai post test kelas eksperimen dan kontrol maka dapat disimpulkan bahwa pembelajaran IPA menggunakan model Complette Sentence berbantu Card efektif terhadap hasil belajar siswa kelas III SDN Ngelowetan Demak. 
Rata-rata nilai tes sebelum diberi perlakuan pada kelas eksperimen sebesar 68,83 dengan 15 siswa (50,00\%) yang dinyatakan tuntas dan 15 siswa yang dinyatakan tidak tuntas. Setelah dilakukan pembelajaran dengan model pembelajaran Complette Sentence berbantu Card diperoleh nilai rata-rata sebesar 81,50 dengan 26 siswa (86,67\%) yang dinyatakan tuntas dan 4 siswa dinyatakan tidak tuntas. Jadi, kelas eksperimen dinyatakan tuntas secara secara klasikal (kriteria ketuntasan belajar klasikal adalah 85\%). Presentase kenaikan hasil belajar siswa sebesar 36,67\%. Meningkatnya nilai rata-rata hasil belajar siswa dikarenakan perhatian siswa dalam proses pembelajaran sangat tinggi yang dimana pada proses pembelajaran menggunakan model pembelajaran Complette Sentence berbantu Card.

Sedangkan pada kelas kontrol (yang tidak menggunakan model pembelajaran Complette Sentence berbantu Card) rata-rata nilai tes sebelum diberi perlakuan pada kelas sebesar 68,75 dengan 11siswa $(39,29 \%)$ yang dinyatakan tuntas dan 17 siswa yang dinyatakan tidak tuntas. Setelah dilakukan pembelajaran tanpa menggunakan model pembelajaran Complette Sentence berbantu Card diperoleh nilai rata-rata sebesar 75,18 dengan 17 siswa (60,71\%) yang dinyatakan tuntas dan 11 siswa dinyatakan tidak tuntas, maka kelas kontrol dinyatakan tidak tuntas secara secara klasikal (kriteria ketuntasan belajar klasikal adalah 85\%).

Keberhasilan belajar pada kelas eksperimen ini tidak serta merta muncul begitu saja, seperti yang diketahui bahwa keberhasilan belajar dipengaruhi beberapa faktor, yakni faktor internal dan faktor eksternal. Dan salah satu faktor eksternal adalah sekolah. Arti sekolah disini hanya bukan berarti gedung sekolahnya saja, melainkan mencakup metode mengajar, relasi guru dengan siswa, pelajaran dan waktu sekolah, standar pelajaran, metode belajar, tugas rumah dan lain sebagainya. Dalam hal ini keberhasilan belajar tentu saja tidak lepas dari model pembelajaran Complette Sentence berbantu Card yang sudah diterapkan peneliti di kelas eksperimen yakni kelas IIIB SDN Ngelowetan Demak.

Hasil penelitian ini menguatkan beberapa hasil penelitian yang ditemukan belakangan ini, diantaranya penelitian yang dilakukan oleh sumerti, dkk (2016) menunjukkan bahwa bahwa terdapat perbedaan yang signifikan keterampilan menulis antara siswa yang dibelajarkan menggunakan model pembelajaran kooperatif tipe Concept Sentence berbantuan gambar berseri dengan siswa yang dibelajarkan menggunakan pembelajaran konvensional (thitung $=2,70>$ ttabel $=2,000$ ). Hasil penelitian lain juga menunjukkan bahwa terdapat perbedaan yang signifikan hasil belajar IPS antara siswa yang mengikuti pembelajaran dengan model pembelajaran kooperatif tipe complete sentence dan siswa yang mengikuti pembelajaran dengan pembelajaran konvensional. Model pembelajaran kooperatif tipe complete sentence berpengaruh terhadap hasil belajar IPS (Agustini, 2017). Selain itu hasil penelitian ini sejalan dengan penelitian yang dilakukan oleh Dita Damayanti, Fransiska (2013) yang mengemukakan bahwa model kooperatif Concept Sentence lebih efektif dibandingkan model pembelajaran langsung pada pembelajaran menulis karangan narasi bagi siswa kelas IV SD seGugus Diponegoro Kecamatan Magelang Tengah ( nilai tobs > t $(0,025 ; 68)$ yaitu $2.8884>1.99547)$. Selain itu, rata-rata nilai keterampilan menulis karangan narasi siswa yang diberi perlakuan dengan model kooperatif Concept Sentence sebanyak 75,77 sedangkan pada kelompok kontrol yang menggunakan model pembelajaran langsung rata-rata nilainya hanya 71,70. hasil penelitian ini memperkuat hasil penelitian sebelumnya.

Uraian di atas memberikan gambaran bahwa model pembelajaran Complette Sentence berbantuan media Card memberikan hasil yang lebih efektif dibandingkan dengan pembelajaran menggunakan metode ceramah. Dari penjelasan diatas tujuan dari penelitian telah dapat dicapai. Jadi dapat disimpulkan bahwa model pembelajaran Complette Sentence berbantuan media Card lebih efektif digunakan dalam pembelajaran.

\section{Simpulan dan Saran}

Berdasarkan hasil penelitian yang telah dilaksanakan dapat disimpulkan sebagai berikut:

Berdasarkan uji $\mathrm{t}$ diperoleh $\mathrm{t}$ hitung $>\mathrm{t}$ tabel yaitu 1,941 >1,70, maka Ha diterima artinya pembelajaran IPA menggunakan model Complette Sentence berbantu Card efektif terhadap hasil belajar siswa kelas III SDN Ngelowetan Demak. Ketuntasan belajar kelas yang dikenai model pembelajaran Complette Sentence berbantu Card mencapai 86,67\% (lebih dari 85\%) sedangkan kelas yang tidak dikenai model pembelajaran Complette Sentence berbantu Card ketuntasan belajar kelasnya hanya 60,71\% (tidak lebih dari 85\%).

Berdasarkan hasil penelitian dan simpulan tersebut, dapat dikatakan bahwa tujuan penelitian dalam penelitian ini telah tercapai. Oleh karena itu disarankan kepada guru-guru hendaknya dapat menjadikan model pembelajaran Complette Sentence Berbantu Card menjadi salah satu model pembelajaran yang harus diterapkan dalam pembelajaran. Tidak hanya model tersebut, model-model pembelajaran dalam lainnya juga lebih ditingkatkan lagi agar kegiatan pembelajaran lebih inovatif dan tidak berkesan membosankan bagi peserta didik. Penelitian ini juga dapat dijadikan refrensi untuk melakukan penelitian lebih lanjut dengan materi atau pokok bahasan yang berbeda, tingkatan kelas yang berbeda, dan tambahan variabel baru sebagai kreativitas baru. 


\section{Daftar Pustaka}

Agustini, Ni Made Dwipayanti, Ketut Pudjawan, Ndara Tanggu Renda. 2017. Pengaruh Model Pembelajaran Kooperatif Tipe Complete Sentence Terhadap Hasil Belajar IPS. e-Journal PGSD Universitas Pendidikan Ganesha Mimbar PGSD Vol: 5 No: 2.

Agustini, Md. , Kt.Dibia, Kd. Suartama. 2014. Pengaruh Model Pembelajaran Tgt Berbantuan Media Flip Chart Terhadap Hasil Belajar IPA Siswa Kelas V SD. Jurnal Mimbar PGSD Universitas Pendidikan Ganesha Jurusan PGSD (Vol: 2 No: 1.

Arikunto, Suharsimi. 2010. Prosedur Penelitian Suatu Pendekatan Praktik. Jakarta: Rineka Cipta.

Arsyad, Azhar. 2013. Media Pembelajaran. Jakarta: PT Raja Grafindo.

Badan Nasional Standar Pendidikan. 2006. Tujuan Pembelajaran Sains Di Sekolah Dasar.

Departemen Pendidikan Nasional. 2006. Strategi Pembelajaran yang Mengaktifkan Siswa. Jakarta: Depdiknas.

Hamalik, Oemar. 2010. Psikologi Belajar Mengajar. Bandung: Sinar Baru Algesindo.

Hamdani. 2011. Strategi Belajar Mengajar. Bandung: Pustaka Setia.

Jaya, I Kd. Putra, I Kt. Adnyana Putra, I Wyn. Darsana. 2014. Model Pembelajaran Picture And Picture Berpengaruh Berbantuan Kemampuan Berpikir Kreatif Siswa Dalam Pembelajaran Ipa Kelas V Sd Gugus Budi Utomo. e-Jurnal Mimbar PGSD Universitas Pendidikan Ganesha Jurusan PGSD Vol: 2 No: 1

Kustandi, Cecep. 2011. Media Pembelajaran Manual dan Digital. Bogor: Ghalia Indonesia.

Huda, Miftahul. 2013. Model-model Pembelajaran dan Pengajaran. Yogyakarta: Pustaka Pelajar.

Sadiman, Arif S dkk. 2011. Media Pendidikan. Jakarta: PT Raja Grafindo Persada.

Saptayanti, Gusti Ayu Kade Emi, I Made Citra Wibawa, Ketut Pudjawan. 2016. Pengaruh Model Pembelajaran Kooperatif Tipe Tgt (Teams Games Tournament) Terhadap Hasil Belajar Matematika. e-Journal PGSD Universitas Pendidikan Ganesha Jurusan PGSD Vol: 4 No: 1

Sudjana, Nana dan Ahmad Rivai. 2013. Media Pembelajaran. Bandung: CV Sinar Baru Bandung.

Sudjana. 2005. Metode Statistika. Bandung: Tarsito

Sugiyono. 2010. Metode Penelitian Pendidikan Pendekatan Kuantitatif, Kualitatif, dan R\&D. Bandung: Alfabeta.

Sumerti, Ni Luh, I Ketut Adnyana Putra, I Wayan Rinda Suardika. 2014. Pengaruh Model Pembelajaran Kooperatif Tipe Concept Sentence Berbantuan Gambar Berseri Terhadap Keterampilan Menulis Siswa Kelas V Sdn 22 Dauh Puri. e-Journal Mimbar PGSD Universitas Pendidikan Ganesha Jurusan PGSD Vol: 2 No: 1.

Susanto, Ahmad. 2013. Teori Belajar Dan Pembelajaran Di Sekolah Dasar. Jakarta: Prenadamedia Group.

Samatowa, Usman. 2016. Pembelajaran IPA di Sekolah Dasar. Jakarta: PT Indeks.

Slameto. 2013. Belajar dan Faktor-Faktor yang Mempengaruhinya. Jakarta: PT Reneka Cipta.

Sukmadinata, Nana Syaodih. 2013. Metode Penelitian Pendidikan. Bandung: PT Remaja Rosdakarya.

Suprijono, Agus.2009. Cooperative Learning. Yogyakarta: Pustaka Pelajar.

Trianto. 2015. Mendesain Metode Pembelajaran Inovatif-Progresif. Jakarta: Kencana.

Undang-Undang Nomor 20 Tahun 2003. Tentang Sistem Pendidikan Nasional.

Warsita, Bambang. 2008. Teknologi Pembelajaran Landasan dan Aplikasinya. Jakarta: PT Rineka Cipta. 
Widodo, Agus dan Nur Salim. 2017. Pengaruh Model Pembelajaran Complete Sentences Didukung Media Gambar Terhadap Kemampuan Melengkapi Puisi Anak Pada Siswa Kelas 3 Sdn Petok Tahun Pelajaran 2016/2017. Simki-Pedagogia Vol. 01 No. 06 Tahun 2017 ISSN : AAAA-AAAA 